\title{
In-situ formation compaction monitoring in deep reservoirs by use of fiber optics
}

\author{
H. Ikeda ${ }^{1}$, S. Kunisue ${ }^{1}$, D. Nohara ${ }^{2}$, K. Ooba ${ }^{3}$, and T. Kokubo ${ }^{4}$ \\ ${ }^{1}$ Kanto Natural Gas Development Co., Ltd., Mobara-shi, Chiba-ken, Japan \\ ${ }^{2}$ Asahi Glass Co., Ltd., Oamishirasato-shi, Chiba-ken, Japan \\ ${ }^{3}$ Godo Shigen Co., Ltd., Chosei-mura, Chiba-ken, Japan \\ ${ }^{4}$ Asano Taiseikiso Engineering Co., Ltd., Uenohara-shi, Yamanashi-ken, Japan \\ Correspondence to: H. Ikeda (h.ikeda@k-and-o-energy.co.jp)
}

Published: 12 November 2015

\begin{abstract}
We have devised a new in situ monitoring method for the amount of stratified compaction in borehole drilled several hundred meters underground. This newly developed epoch-making monitoring system differs from conventional monitoring methods for land subsidence in that it is designed to continuously monitor the amounts of displacement in several intervals separately, using optical fibers fitted in the sensor assembly. This report presents results from a deep observation well. This is a continued report from the previous one on EISOLS 2010.
\end{abstract}

\section{Introduction}

Gas fields distributed in the Southern Kanto region in Japan - collectively known as the Minami kanto natural gas field - are ranked among the world's largest for natural gas dissolved in water. In particular, the Kujukuri region of Chiba Prefecture not only has abundant reserves of natural gas dissolved in water but also a high concentration of iodine found in brine (in which natural gas is dissolved) that represent precious domestically-produced resources for a resource-poor country like Japan (Fig. 1). The problems posed by land subsidence in this area were manifested in the late 1960s. Although land subsidence in recent years has been reduced in many areas, some places still experience land subsidence at levels exceeding $10 \mathrm{~mm}$ per annum. The eight private corporations currently engaged in development in this area are making efforts to address environmental problems, including land subsidence, by organizing the Environment Committee of the Japan Natural Gas Association and Keiyo Natural Gas Association.

\section{In situ formation compaction monitoring}

Levelling is one thing most traditional methods. In recent years, GPS or SAR (synthetic aperture radar) surveys us- ing artificial earth satellites measurements are also increasing gradually. However, these methods observe relative changes in the ground surface. A purpose of this study is to understand the actual in situ formation compaction in a certain underground section (Fig. 2).

The monitoring site is located the area where has an annual ground deformation rate of at least $10 \mathrm{~mm}$ by levelling every year. In this area, the natural gas dissolved in water is produced by pumping up brine from formations several hundred meters to $1000 \mathrm{~m}$ in depth. The gas reservoirs of the Minami kanto gas field consist of alternation of unconsolidated sandstone and mudstone.

The monitoring system basically consists of the settlement gauges and rods used in displacement transmission (Fig. 3). Features of this system are applied to the optical fibers as settlement gauges and transmission lines, with an eye on deformation measuring technology through optical fiber. The use of optical fiber is advantageous in terms of high accuracy as settlement gauges, which will most likely enable measurement of underground deformations. And the optical fibers make long distance communication possible.

In the measurement principle of this system, settlement gauges are installed at several positions inside the borehole at a certain interval to monitor changes within the interval length. The settlement gauges are interconnected with rods. 


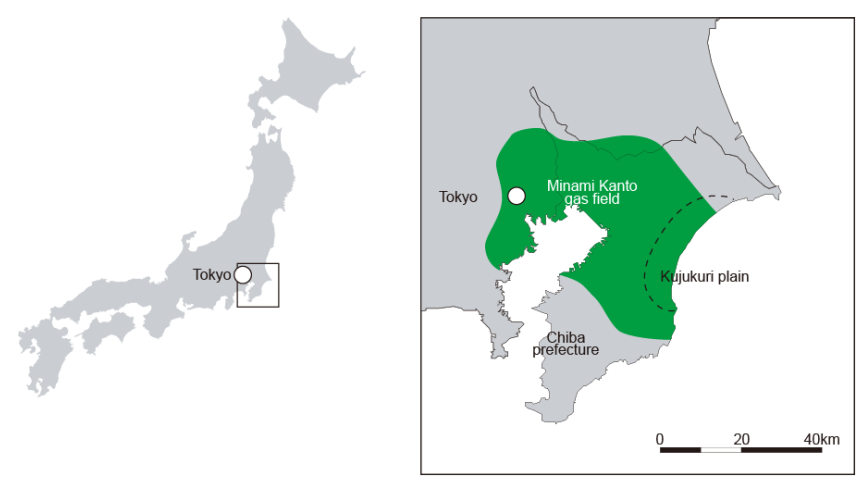

Figure 1. Minami kanto gas field.

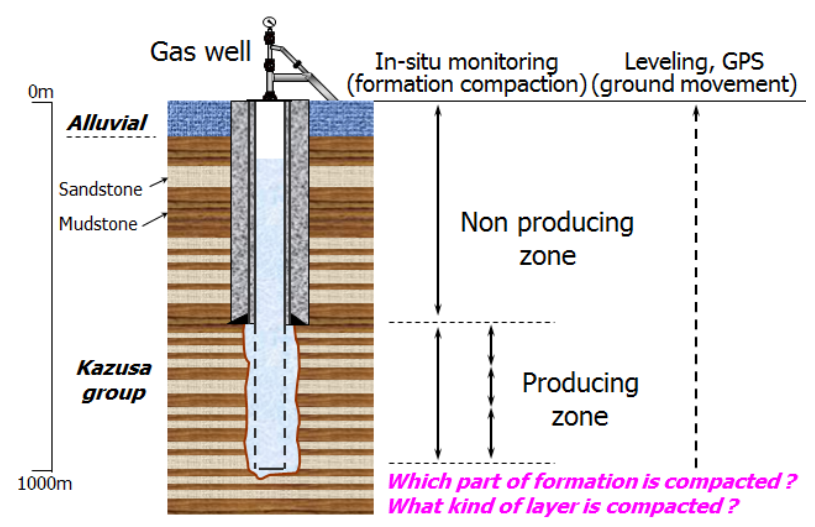

Figure 2. Concept of in situ formation compaction monitoring.

Each rod is fixed with an anchor at the top end; its lower end is directly connected with an optical fiber sensor inside the lower settlement gauge. The optical fiber sensor (made of stainless plate) is designed to bend when pushed down by the rod. The lower part of the settlement gauge is equipped with an anchor mechanism that fixes the gauge directly to borehole. When the settlement gauge drops to the predetermined depth, the metal pad will expand in three directions as a result of the water pressure and be pressed against the side wall to be anchored. The pad is mechanically designed to prevent it from shrinking after being expanded.

\section{Observation system and results}

In order to verify the reliability of the observation system, and sorted out problems on the construction of measurement system applying to the strata of the actual test well depth of $80 \mathrm{~m}$ equipped prototype tool, conducted demonstration tests. It was confirmed that in a pilot test well off the $10 \mathrm{~m}$ water well and pumping artificial contraction stratum, layer compaction can be observed properly. Then $800 \mathrm{~m}$ deep borehole (the observation well) was drilled at monitoring site and, later, the settlement gauge were installed in the borehole on June 2012. Continuous monitoring was launched
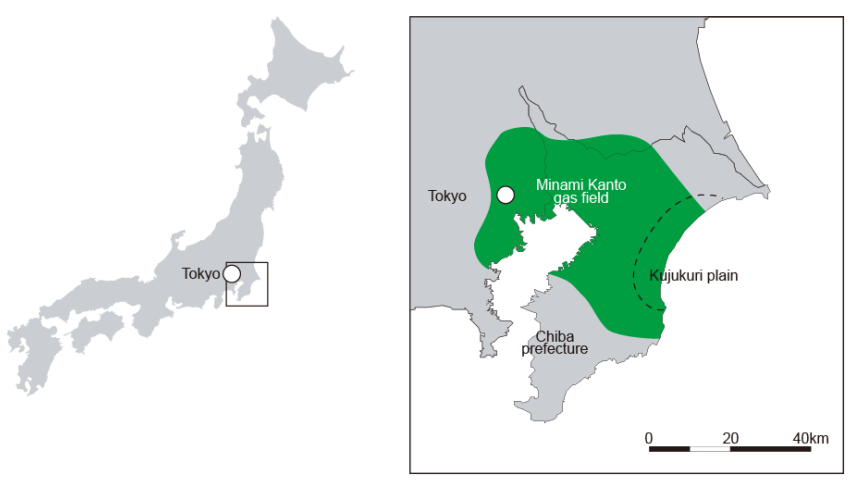

Figure 3. In situ formation compaction monitoring method.

in September 2012. Monitoring in five natural gas production zone has been conducting. Settlement gauges installed in the hole observed during the nearly two and a half years that working properly except for the part. Displacement data are measured in each settlement is in optical fiber signals to Earth, $30 \mathrm{~min}$ in every recorded in the recording equipment. The result shows that trends of formation compaction are not same among observation intervals. Also rate of formation compaction is not constant. The observation will be continued to collect data in the future. On the other hand, it has turned out that the observation equipment on the ground is affected by changes in temperature. Because it is difficult to constant temperature in the data recording equipment, relationship between temperature and change in wavelength of receiving light has been adopted to correct data.

At the time of the April 2015, total compaction of all observation intervals is $1.2 \mathrm{~mm}$ for about two and a half years.

\section{Conclusions}

The observation system based on optical fiber sensing technology has been developed and installed in the natural gas reservoir. It has monitored and recorded formation compaction data for about two and a half years from the observation starting without big trouble. This system has been running and we will continue observation. However, we consider that the examination about the correction of the observed data is required.

Acknowledgements. This research was carried out by the support for application of new technologies and technical studies program which Japan Oil, Gas and Metals National Corporation (JOGMEC) undertook. 